\title{
EaD e Aprendizagem Organizacional: Uma Análise de Relação e Possibilidades.
}

\author{
Jacqueline Keller (UFSC, jacquekeller@yahoo.com.br) \\ Neri dos Santos (UFSC, neri@egc.ufsc.br) \\ Raquel Bohnen Busanello (UFSC, raquelbusanello@terra.com.br) \\ Sônia Novaes Estácio (UFSC, sonianovaestacio@yahoo.com.br)
}

\begin{abstract}
Resumo: O artigo tem por objetivo discutir a relação entre dois temas emergentes nos contextos educacionais e empresariais, o EaD e a aprendizagem organizacional, apresentando seus principais conceitos, identificando as características e possibilidades do $\mathrm{EaD}$, bem como os facilitadores para a aprendizagem organizacional. A partir de uma revisão da literatura, o eixo central dessa discussão concentra-se em analisar a relação entre estes dois elementos de pesquisa, concluindo com as possibilidades de contribuição do $\mathrm{EaD}$ na aprendizagem organizacional, proporcionando às organizações empresarias, importantes reflexões acerca das múltiplas oportunidades da aplicação de EaD como instrumento de aprendizagem organizacional e de agregar valor ao empreendimento.
\end{abstract}

Palavras chave: Aprendizagem Organizacional, Educação a Distância, Organizações.

Abstract: The article argues the relation between two emergent subjects in the contexts educational and enterprise: the Distance Education and Organizational Learning: It in the distance presents of distinct form the main concepts of Education and Organizational Learning. It in the distance identifies to the characteristics and possibilities of the Education as well as the facilitators for the Organizational Learning. In the central axle it is concentrated in analyzing the relation in the distance enters these two elements of research concluding for the possibilities of contribution of the Education in the Organizational Learning, providing to the organizations important reflections concerning the multiple chances of the Distance Education as instrument of Organizational Learning and to add value to the enterprise.

Key words: Organizational Learning, The Distance Education, Organizations.

\section{INTRODUÇÃO}

A educação à distância - EaD, se caracteriza, principalmente, pela não presencialidade, de alunos e professores em um ambiente físico. Este tipo de modalidade tem proporcionado uma grande procura ao sistema permitindo à aqueles que tinham dificuldades de acesso às salas de aula, passassem a buscar a modalidade à distância, principalmente, aproveitando a questão do avanço das tecnologias e da maior acessibilidade. A evolução tecnológica tem ajudado no desenvolvimento de uma EaD muito mais interativa contrapondo-se a modelos instrucionistas e lineares. A EaD configura-se hoje, como uma modalidade regular, utilizando-se de diferentes linguagens, como a escrita, a imagem a informática.Gomes \& Lopes (2000) consideram que a $\mathrm{EaD}$ tem sido cada vez mais reconhecida como uma modalidade educativa alternativa para atender às exigências da educação ao longo da vida. 
As mudanças em pauta no mundo contemporâneo face à economia globalizada e o avanço incomensurável das tecnologias da informação e da comunicação e, em consequiência, a configuração de um novo paradigma societal, exige a constante aquisição e aplicação de novos conhecimentos. Nessa nova sociedade, para alguns, denominada "Sociedade Tecnológica", "Sociedade da Informação e do Conhecimento" e, para outros, "Sociedade Educativa", o conhecimento é considerado propulsor do desenvolvimento. Nesse contexto, a $\mathrm{EaD}$ vem adquirindo grande importância, sempre traduzida no empenho de um crescente número de instituições que a assumem para a oferta de seus programas de formação, cujas demandas aumentam exponencialmente.

A aprendizagem organizacional, por sua vez, representa condição para as organizações vencerem e permanecerem no dinâmico mundo dos negócios a definição de NEVIS et al (1988, p.184) para a aprendizagem organizacional como sendo: "a capacidade ou os processos dentro da organização destinados a manter ou melhorar o desempenho com base na experiência" corroboram esta afirmativa, e envolvem por sua vez a aquisição, o compartilhamento e a utilização do conhecimento, donde depreende-se a expectativa de que o conhecimento adquirido seja explicitado e aplicado concretamente. Porém, uma parcela das organizações está estruturada em redes, grupos, filiais, distantes geograficamente, o que pode dificultar a interação presencial, "o corpo a corpo" e a aplicação concreta do conhecimento.

A EaD tem sido, cada vez mais, reconhecida como uma modalidade educativa alternativa para atender as exigências da educação, principalmente no que tange as questões ligadas à aprendizagem organizacional, tendo em vista as mudanças no mundo contemporâneo.

Assim o objetivo desse estudo é motivado pelo interesse em identificar se a prática da EaD pode ser agente facilitador para aprendizagem organizacional e conseqüentemente para difundir o conhecimento nas organizações.

$\mathrm{O}$ artigo inicia com o resgate bibliográfico dos conceitos de educação à distância e aprendizagem organizacional, bem como dos elementos facilitadores a estes processos, remetendo posteriormente ao estudo da inter-relação entre os dois temas centrais, procurando identificar as possibilidades de contribuição da educação à distância na aprendizagem organizacional.

\section{METODOLOGIA}

O estudo propõe explorar através de levantamento bibliográfico, os termos educação à distância e aprendizagem organizacional, visando responder a seguinte questão de pesquisa: Como a educação à distância pode influenciar na aprendizagem organizacional? Assim, procedeu-se pesquisa bibliográfica, acerca dos temas centrais: educação à distância, suas possibilidades e características, bem como o que é aprendizagem organizacional e também seus elementos facilitadores. Posteriormente procurou-se estabelecer a relação entre a educação à distância e a aprendizagem organizacional remetendo-se as considerações finais.

\section{REFERENCIAL TEÓRICO}

\subsection{Educação à distância - EaD}

O momento atual demonstra cada vez mais que o conhecimento e a capacidade de aprender ao longo da vida tornaram-se uma condição essencial para o desenvolvimento humano e consequientemente uma riqueza para as nações.

Assim a EaD contribui significativamente para o desenvolvimento tanto dos indivíduos quanto dos países, pois apresentam características de flexibilidade de espaço e 
tempo que se adaptam as diversas necessidades. Para tanto se faz necessário entender o conceito de EaD segundo alguns autores. Para Moran (2002) a EaD é o processo de ensinoaprendizagem, mediado por tecnologias onde professores e alunos estão separados espacial e ou temporariamente.

Moore e Kearsley (1996, p.11) apresentam a seguinte definição para EaD: "Educação a distância é a aprendizagem planejada que geralmente ocorre num local diferente do ensino e, por causa disso, requer técnicas especiais de desenho de curso, técnicas especiais de instrução, métodos especiais de comunicação através da eletrônica e outras tecnologias, bem como arranjos essenciais organizacionais e administrativos".

Steil\&Cols(2005) em seu artigo: Atitudes com relação à educação à distância em uma universidade, utilizam a abordagem de Aretio, que identifica algumas características que são necessárias para considerar um curso ou programa como EaD: a quase permanente separação do professor ou formador e do aluno ou participante no espaço e no tempo; o estudo independente, em que o aluno controla o tempo e o espaço e determinados ritmo de estudo.

Para Gomes \& Lopes (2000) a EaD é vista como um distinto modo de ensinar e aprender, pois transcende a modalidade à distância como uma questão única geográfica e espacial. E reforçam dizendo que a espacialidade, característica da $\mathrm{EaD}$, não deve ser vista como elemento impeditivo ou dificultador, mas reconhecido como elementos intrínsecos, cuja superação ocorre, por um lado, devido ao paradigma de ensino-aprendizagem adotado, e por outro mediante o sistema de comunicação utilizado para mediar o processo educativo.

Atualmente existem diferentes formas de educação, existe a forma presencial, que é a tradicional dos cursos regulares, onde os alunos e professores encontram-se em sala de aula, ou seja, no mesmo local físico. O semipresencial, onde parte das aulas é da forma presencial e outra parte a distância na modalidade virtual. Há ainda a educação totalmente à distância onde alunos e professores não dividem espaço físico, eles estão separados no espaço e tempo, mas pode em algum momento ter encontros presenciais.

Moran (2002) relembra que a EaD pode ocorrer nos mesmos níveis do ensino regular, seja fundamental, médio, superior e pós-graduação. No entanto, ele adverte que a educação à distância, também conhecida como EaD é mais adequada para educação de adultos, principalmente, os que já possuem experiência consolidada de aprendizagem individual, o que acontece nos ensinos de graduação e pós-graduação.

Segundo Moran (2002), ainda hoje entende-se que aula é um espaço e um tempo determinado, porém esse espaço e tempo serão flexíveis. "O professor continuará dando aula, e enriquecerá esse processo com as possibilidades que as tecnologias interativas proporcionam: para receber e responder mensagens dos alunos, criar listas de discussão e alimentar continuamente os debates e pesquisas com textos, páginas da Internet, até mesmo fora do horário específico da aula. Há uma possibilidade cada vez mais acentuada de estarmos todos presentes em muitos tempos e espaços diferentes. Assim tanto professores quanto alunos estarão motivados, entendendo aula como pesquisa e intercâmbio. Nesse processo, o papel do professor vem sendo redimensionado e cada vez mais ele se torna um supervisor, um animador, um incentivador dos alunos na instigante aventura do conhecimento".

Para Polak e Martins (2000), o aspecto essencial da educação a distância não é só à distância, mas o redimensionamento espaciotemporal no processo de ensino aprendizagem. Conseqüentemente é possível atingir uma área muito maior, o que possibilita pessoas de locais longínquos e também as mais próximas terem acesso à educação. Ao mesmo tempo haverá um redimensionamento do tempo. É possível atingir também aquelas pessoas que não possuem tempo para frequientarem as aulas nos horários típicos, resumidamente é possível atingir um número muito maior de pessoas do que o ensino presencial convencional pode atingir. 
KAYE (1979) estabelece dez aspectos como caracterizadores da educação à distância: a população estudantil dispersa geograficamente e, em particular, aquela que se encontra em zonas periféricas que não dispõe das redes das instituições convencionais; Administra mecanismos de comunicação múltipla que permitem enriquecer os recursos de aprendizagem , a dependência da educação face-a-face; Favorece a possibilidade de melhorar a qualidade da instrução ao designar a elaboração dos materiais aos melhores especialistas; Estabelece a possibilidade de personalizar o processo de aprendizagem para garantir uma seqüência acadêmica que responda ao ritmo do rendimento do estudante; Promove a formação da habilidade para o trabalho independente e para um esforço auto-responsável; Formaliza vias de comunicação bidirecionadas e freqüentes relações de mediação dinâmicas e inovadoras; Garantia a permanência do estudante em seu meio cultural e natural com o qual se evitam êxodos que incidem no desenvolvimento regional; Alcança níveis de custos decrescentes, já que depois de um forte gasto inicial se produz coberturas de ampla margem de expansão; Realiza esforços que permitem combinar a centralização da produção com a centralização do processo de aprendizagem; Precisa de uma modalidade capaz de atuar com eficácia e eficiência na atenção de necessidades conjunturais da sociedade, sem os desajustes gerados pela separação dos usuários de seus campos de produção.

A UNESCO/UNED(Madri, 1998) no documento Aprendizagem Aberta e a Distância - Perspectivas e Considerações propõe que a comunidade internacional comprometa-se com o desenvolvimento da educação à distância pelas razões básicas que indica, das quais buscou-se sintetizar as principais, a seguir apresentadas e que permitem refletir acerca da importância e das relevantes possibilidades de desenvolvimento com adoção da educação à distância: a EaD facilita o cumprimento do princípio de igualdades de oportunidades, explorando simultaneamente as possibilidades de novas tecnologias de informação e comunicação; Responde as políticas da UNESCO, que incentiva o seu aproveitamento a organizações governamentais ou não; ao estudante por compatibilizar trabalho e estudo, dando-lhe maiores oportunidades, libertando-o de barreiras de tempo, espaço, sócio-culturais, habituando-o a organizar de modo flexível seu trabalho; ao empresário por garantir um melhor custo/ benefício, pois evita deslocamentos que interrompem as atividades profissionais; ao governo, pois permite incrementar a oferta educativa e chegar a grupos sociais com dificuldades de acesso: Promove a inovação; Maior flexibilidade para atender novas necessidades; Maiores oportunidades de educação permanente; A formação do professorado; a formação profissional; A educação superior; Novas formas de aprendizagem baseadas em tecnologias de comunicação; Custo/benefício.

Com o propósito de melhor apreciar os itens elencados pelos respectivos autores, buscou-se compilar referidos itens numa tabela:

Tabela 1- Relação entre as características e possibilidades e seus respectivos autores

\begin{tabular}{|l|l|}
\hline CARACTERÍSTICA/ & AUTORES \\
POSSIBILIDADE & \\
\hline Separação geográfica & Keegen, Kaye \\
\hline Comunicação bidirecional & Keegen, Holmberg \\
\hline Ensino em grupo & Keegen \\
\hline Industrialização & Keegen, Holmberg \\
\hline Estudo individual & Holmberg \\
\hline Comunicação massiva & Holmberg \\
\hline Uso de Tecnologia & Holmberg \\
\hline Melhorar qualidade da instrução & Kaye \\
\hline Personalizar o processo de aprendizagem & Kaye \\
\hline Prepara para trabalho independente & Kaye \\
\hline Custos decrescentes & Kaye \\
\hline Permanência no próprio meio cultural & Kaye \\
\hline &
\end{tabular}




\begin{tabular}{|l|l|}
\hline Variedade de experimentos em pouco tempo & Ghisi \\
\hline Interatividade & Ghisi \\
\hline Socialização & Ghisi \\
\hline Criatividade & Ghisi \\
\hline Igualdade de Oportunidades & UNESCO \\
\hline $\begin{array}{l}\text { Combinar centralização da produção com centralização do } \\
\text { processo de aprendizagem }\end{array}$ & UNESCO \\
\hline Compatibiliza trabalho e estudo & UNESCO \\
\hline Melhor custo/benefício às empresas & UNESCO \\
\hline Inovação & UNESCO \\
\hline Flexibilidade & UNESCO \\
\hline Formação profissional & UNESCO \\
\hline
\end{tabular}

Fonte: Elaborado pelas autoras.

Da análise dos autores citados acerca das características e possibilidades da educação à distância, entende-se que tais características e possibilidades podem se constituir em vantagens se comparadas à educação convencional. Assim entende-se que as facilidades e características da Educação à Distância, embora tenham sido denominadas de forma diferente resumem-se em alguns aspectos como: maior acesso à educação, flexibilidade de tempo e horário, encurtamento de distância. Além disso, identifica-se que a Educação à Distância pode representar vantagens para diversos setores da sociedade: o individuo, as empresas, a sociedade, o governo e as mais diversas formas de organização.

\subsection{Aprendizagem organizacional}

A aprendizagem num sentido amplo pode ser entendida como um processo que ocorre em todas as atividades humanas, e nas diversas etapas da vida, desde o nascimento até a velhice contemplando os diversos ambientes em que o indivíduo encontra-se inserido: familiar, comunitário, escolar e de trabalho.

Em geral, existe uma tendência a pensar em aprendizagem como um processo em que os indivíduos adquirem novos conhecimentos e percepções promovendo mudanças em seu comportamento e suas ações. O cerne da questão a ser respondida neste item é: Aprendizagem organizacional difere de aprendizagem individual? Em especial, o que é aprendizagem organizacional?

Dusya e Crossan (2005), entendem que Aprendizagem Organizacional é o processo de mudança no pensamento individual e compartilhado e na ação, que é afetada por e se torna característica da organização.

Argyris (1978) define aprendizagem organizacional como um processo de detecção e correção de erros, já para Kim (1993) aprendizagem é definida como aumento da capacidade de uma organização realizar ações eficazes. Necessário se faz analisar também, como ela ocorre, como se dá o processo de aprendizagem organizacional.

De acordo com Garvin (1993), uma organização que aprende é aquela capaz de criar, adquirir e transferir conhecimento e de modificar o seu comportamento, refletindo os novos conhecimentos e percepções. Sob o enfoque da melhoria contínua, o autor descreve cinco práticas para que a organização possa aprender sempre: Resolução sistemática de problemas; Experimentação; Aprendizagem com a história passada; Aprendizagem com os outros; Difusão do conhecimento pela organização.

Nonaka e Takeuchi (1995) em relação à aprendizagem organizacional apontam três condições que favorecem a criação efetiva do conhecimento: caos criativo, que acontece em situações de crise; redundância: justaposição consciente de informações, atividades e 
responsabilidades que encoraja a comunicação freqüente e ajuda na criação de uma base cognitiva comum e; diversidade, na medida que a quantidade de informação a ser processada aumenta pela redundância consciente ou por outros fatores as pessoas devem dispor das informações para acesso imediato.

Em relação à aprendizagem individual Kim (1998) a caracteriza como aquela que ocorre a partir da experiência, da observação e da capacidade que o indivíduo tem de refletir e avaliar a situação, gerando estruturas cognitivas, modelos interpretativos e rotinas pessoais de trabalho. Para Kim a aprendizagem se torna organizacional no momento em que esses modelos interpretativos e rotinas são compartilhados pelos membros da organização.

Neste mesmo sentido, Probst e Büchel (1997) referem-se à aprendizagem individual como produto da reflexão de cada pessoa singular que muda suas estruturas cognitivas e, conseqüentemente, seus comportamentos.

O modelo conceitual de gerenciamento da aprendizagem organizacional apresentado por Pawlowsky (2003) considera quatro dimensões integrativas à aprendizagem Organizacional: diferentes níveis de análise, considerando aprendizagem individual e aprendizagem organizacional, de grupo, através do compartilhamento, inter e intraorganizacional; diferentes modos de aprender, pelos modos cognitivo, cultural ou de ação; diferentes níveis de aprendizagem: de laço simples, focada na detecção e correção de erros, duplo, de ajuste a demandas ambientais ou deutero, aprender a aprender; diferentes fases de um processo de aprendizagem coletiva que envolvem a identificação da informação relevante à aprendizagem, a troca ou difusão do conhecimento, a integração do conhecimento em sistemas de conhecimento existentes e a transformação do novo conhecimento adquirido em aplicação nas práticas organizacionais.

Depreende-se dos conceitos analisados que a aprendizagem organizacional decorre da aprendizagem individual disseminada, através da integração entre as pessoas, que passam a compartilhar valores, crenças. Observa-se que, alguns dos autores citados referem como condição à aprendizagem organizacional a ocorrência de mudanças. Mudanças estas advindas de indivíduos que inter-relacionam-se, comunicam-se sendo influenciados e gerando influência.

Porém ao considerar que as organizações contam com pessoas dotadas de conhecimento, habilidades e experiência, por que nem sempre é possível transferir o conhecimento individual e gerar aprendizagem organizacional? Quais são os fatores que facilitam ou dificultam a aprendizagem organizacional?

De acordo com Garvin (2002) o processo de aprendizagem nas organizações é obtido mediante o comprometimento das pessoas em um processo de gestão lento e profundo, demanda tempo para reflexões e análises, para planejar e avaliar o sistema de trabalho corrente. Diante disso reitera-se a relevância de se considerar as práticas que facilitam ou produzem aprendizagem organizacional.

Garvin (2002) apresenta três maneiras da organização melhorar e acelerar sua capacidade de aprender: tornar o ambiente mais saudável para o aprendizado; melhorar a infra-estrutura de aprendizagem e; aperfeiçoar o conhecimento e as habilidades de aprendizagem das pessoas.

Para Ulrich e Vonglinow (1993); Slater e Narver (1995) as oportunidades para aprendizagem existem muito além de uma sala de aula com palestras, aulas e seminários, elas são encontradas em interações com clientes, fornecedores e concorrentes, em novas atribuições, no relacionamento com outros empregados e outros setores, bem como na 
estrutura, na tecnologia, no processo administrativo e gerencial e no desenvolvimento de produtos e serviços.

Já Argyris e Schön (1978) ressaltam a importância dos mecanismos de transferência da aprendizagem. No momento em que for possível a compreensão clara de transferência do conhecimento individual para o organizacional, haverá melhores condições para gerenciar o processo de aprendizagem, a aprendizagem torna-se assim, coerente com o objetivo, visão, missão e valores da organização.A essência da aprendizagem organizacional está na capacidade de integrar o conhecimento dos indivíduos. Segundo ele, o propósito é que processo decisório permita a integração do conhecimento especializado através de toda a organização.

\section{EDUCAÇÃO à DISTÂNCIA e APRENDIZAGEM ORGANIZACIONAL}

A celeridade das mudanças observadas no complexo mundo das organizações bem como a competitividade na busca pela sobrevivência ou por uma maior fatia no mercado têm levado as empresas a repensarem o seu comportamento. As formas de aquisição e disseminação do conhecimento tem sido cada vez mais alvo de análise e discussão dentro das empresas.

Hoje as organizações estão percebendo que muito mais do que simples falácia, o conhecimento e a aprendizagem organizacional são imprescindíveis para vencer e permanecer no dinâmico mundo dos negócios. A necessidade é cada vez maior de extrair o máximo de valor do conhecimento consolidando-o num processo de aprendizagem organizacional e transformando-o em novas oportunidades de negócio.

Nas organizações o conhecimento está normalmente embutido nos documentos, repositórios, rotinas, processos, práticas e normas organizacionais. Cabe então, analisar, como as organizações podem melhor abstrair e disseminar o conhecimento? Como possibilitar a aprendizagem organizacional? Natural que a capacidade de a organização absorver e transferir o conhecimento depende do tipo de conhecimento envolvido e da cultura da organização.

Uma das estratégias usadas pelas empresas é o investimento na aprendizagem organizacional, entendida como: "uma busca proposital com o objetivo de reter e incrementar a competitividade, a produtividade, e a inovação em circunstâncias de incerteza tecnológica e de mercado, pois, quanto maiores as incertezas, maior a necessidade de aprender" (DODGSON, 1993 p. 378)

A organização necessita criar condições para aprendizagem individual e organizacional, buscando de todas as formas eliminar as barreiras que limitam a aprendizagem organizacional. Uma das alternativas para ampliar as possibilidades é exatamente através da EaD.

Analisando-se as características e possibilidades da EaD identifica-se claramente que tal modalidade de aprendizagem representa possibilidade de contribuir com a aprendizagem organizacional. Tal perspectiva torna-se mais evidente ao analisar-se o quadro (1) onde se correlaciona às características ou possibilidades da $\mathrm{EaD}$ com a possibilidade de aplicação no âmbito das organizações.

\begin{tabular}{|l|l|}
\hline $\begin{array}{l}\text { CARACTERÍSTICA/ } \\
\text { POSSIBILIDADE } \\
\text { DA EDUCAÇÃO A DISTÂNCIA }\end{array}$ & $\begin{array}{l}\text { POSSIBILIDADES DE CONTRIBUIÇÃO PARA A } \\
\text { APRENDIZAGEM ORGANIZACIONAL }\end{array}$ \\
\hline Separação geográfica & $\begin{array}{l}\text { Encurta distâncias ao adotar os meios característicos } \\
\text { da EAD. Unifica cultura visão missão, práticas e } \\
\text { procedimentos }\end{array}$ \\
\hline
\end{tabular}




\begin{tabular}{|c|c|}
\hline Comunicação bidirecional & Diálogo favorecendo intercâmbio de conhecimento \\
\hline Ensino em grupo & $\begin{array}{l}\text { Maior possibilidade de questionamentos, } \\
\text { contribuições, críticas e troca de experiências }\end{array}$ \\
\hline Industrialização & $\begin{array}{l}\text { Divisão do trabalho, mecanização, automação, } \\
\text { controle e verificação }\end{array}$ \\
\hline Estudo individual & $\begin{array}{l}\text { Profissionalização e especialização do indivíduo a } \\
\text { qualquer tempo e lugar }\end{array}$ \\
\hline Comunicação massiva & Diminuição de custos, padronização, senso comum \\
\hline Uso de Tecnologia & $\begin{array}{l}\text { Utilização de mecanismos múltiplos de comunicação } \\
\text { da comunicação escrita à virtual }\end{array}$ \\
\hline Melhorar qualidade da instrução & $\begin{array}{l}\text { Uso de especialistas na elaboração de conteúdo da } \\
\text { aprendizagem }\end{array}$ \\
\hline \multicolumn{2}{|l|}{ Personalizar o processo de aprendizagem } \\
\hline Prepara para trabalho independente & Maior autonomia, iniciativa e condições de decisão \\
\hline \multicolumn{2}{|l|}{ Custos decrescentes } \\
\hline Permanência no próprio meio cultural & $\begin{array}{l}\text { Permanência na organização. Reter e disseminar o } \\
\text { conhecimento }\end{array}$ \\
\hline Variedade de experimentos em pouco tempo & Troca de experiências e resultados obtidos \\
\hline Interatividade & Interações síncronas e assíncronas \\
\hline Socialização & Disseminação de conhecimentos e experiências \\
\hline Criatividade & Inovação, diferenciação, racionalização \\
\hline Igualdade de Oportunidades & $\begin{array}{l}\text { Inclusiva. Permite a participação de todos os níveis } \\
\text { da empresa }\end{array}$ \\
\hline \multicolumn{2}{|l|}{$\begin{array}{l}\text { Combinar centralização da produção com } \\
\text { centralização do processo de aprendizagem }\end{array}$} \\
\hline Compatibiliza trabalho e estudo & $\begin{array}{l}\text { Permite conciliar ao colaborador atividade } \\
\text { profissional e de estudo, inclusive no próprio local de } \\
\text { trabalho }\end{array}$ \\
\hline Melhor custo/benefício às empresas & $\begin{array}{l}\text { Evita deslocamentos e interrupção das atividades } \\
\text { profissionais, maior número de colaboradores com } \\
\text { acesso ao mesmo conhecimento. }\end{array}$ \\
\hline Inovação & $\begin{array}{l}\text { Novas métodos de realizar o trabalho, novos } \\
\text { conhecimentos, novos produtos }\end{array}$ \\
\hline Flexibilidade & Liberação temporal, geográfica \\
\hline Formação profissional & Qualificação e ampliação dos conhecimentos \\
\hline
\end{tabular}

Tabela 2- Relação entre EaD e Aprendizagem Organizacional

Fonte: Elaborado pelas autoras.

O quadro em questão reitera a assertiva de que a aprendizagem organizacional é um campo vasto de pesquisa. No intuito de melhor possibilitar a compreensão e organização das características e possibilidades da $\mathrm{EaD}$ como facilitadores à aprendizagem organizacional, resgata-se o modelo conceitual de gerenciamento da Aprendizagem Organizacional, segundo Pawlowsky (2003) que a subdivide em quatro dimensões integrativas.

No artigo identifica-se na inter-relação, considerando as possibilidades de contribuição da Educação à Distância para Aprendizagem Organizacional como mais presentes três dessas dimensões do modelo conceitual de gerenciamento da Aprendizagem Organizacional. São elas: no nível de análise no que tange às análises individual, interpessoal, intra e interorganizacional e; em relação aos diferentes modos de aprender, envolvendo os modos cognitivo, cultural e de ação; e finalmente no que diz respeito ao processo de aprendizagem envolvendo as fases de identificação, troca ou difusão, integração e transformação do conhecimento em ação.

\section{CONSIDERAÇÕES FINAIS}


Não resta dúvida de que a evolução tecnológica tem ajudado ao desenvolvimento de uma Educação à Distância muito mais interativa, contrapondo-se a modelos instrucionais e lineares. A EaD configura-se hoje como uma modalidade regular, utilizando-se de diferentes linguagens, como a escrita, a imagem e a informática.

Dessa forma, e com o desenvolvimento das tecnologias da comunicação e da informação a EaD tem modificado seu conceito ao longo de quatro gerações e conforme Freire (1987) hoje está centrada em desenvolver propostas que ultrapassem a visão bancária de educação.

A EaD tal como definida pelo próprio MEC e em consonância com a maioria dos autores apresentados no presente estudo, é aquela em que o aluno constrói conhecimento - ou seja, aprende - e desenvolve competências, habilidades, atitudes e hábitos relativos ao estudo, à profissão e à sua própria vida, no tempo e local que lhe são adequados, não com a ajuda em tempo integral da aula de um professor, mas com a mediação de professores (orientadores ou tutores), atuando ora a distância, ora em presença física ou virtual, e com o apoio de sistemas de gestão e operacionalização específicos, bem como de materiais didáticos intencionalmente organizados, apresentados em diferentes suportes de informação, utilizados isoladamente ou combinados, e veiculados através dos diversos meios de comunicação.

A maioria das organizações contemporâneas dispõe de recursos necessários ao desenvolvimento de projetos de $\mathrm{EaD}$ que, como se verificou através das características e possibilidades, em muito podem contribuir para a aprendizagem organizacional. Necessário se faz, contudo, que as organizações busquem transpor as próprias barreiras e as barreiras inerentes à Aprendizagem organizacional, criando um ambiente que facilite a aprendizagem. Para tanto, a organização precisa ter projetos, planejar a médio e longo prazo, fazer sua própria estruturação, elaborar seus parâmetros de aprendizagem organizacional.

A educação a distância então surge para as organizações como uma importante estratégia para propiciar a educação continuada dos colaboradores, dotando-o de mais instrumentos para o bom desempenho de suas atribuições. Ressalte-se ainda, que o processo de aprendizagem contínua é requisito para a renovação e adequação das organizações no enfrentamento dos desafios impostos pelas mudanças no ambiente sócio-político-econômico e das exigências e uma sociedade mais consciente e mobilizada.

A EaD, pelas características e possibilidades que apresenta, se bem conduzida, estruturada num projeto consistente e alinhado à organização demonstra ser uma excelente alternativa para a aprendizagem organizacional e, por conseguinte, para ampliar sua competitividade.

A pesquisa demonstrou que há poucos estudos realizados, onde se estabelece essa relação entre a educação à distância e a aprendizagem organizacional, o que demonstra a necessidade de realização de mais estudos no sentido de confirmar a relação apresentada.

\section{REFERÊNCIAS}

ARGYRIS, C. \& SCHON, D. Organizational Learning: A theory of action perspective. Wesley, Massachusetts, 1978.

DUSYA, Vera e CROSSAN, Mary. Organizational learning and knowledge management: toward an integrative framework. In: EASTERBY-SMITH; LYLES, Marjorie (eds). Handbook of Organizational Learning and Knowledge Management. Malden: Blackwell, p. 122-141, 2005.

DODGSON, Mark. Organizational Learning: a review of some literatures. Organizations Studies, v.14, n. 3, p. 375-394, 1993.

FREIRE, P. Pedagogia da Autonomia. Paz e Terra, 1998. 
GARVIN, D. Building a Learning Organization. Harvard Business Review, July - Aug 1993, p. 45-49.

GOMES, C.J.A.; LOPES, R.G.F.. Gestão de sistemas de educação à distância: proposta de reflexão e prática em ambiente on-line. $\mathrm{O} 3^{\circ}$ Curso de Especialização em Educação a Distância, desenvolvido pela UnB/FE- Brasília 2000.

NAYAK, P.R., MAIRA, A.N.; BRAGAR, J.L.. Aprender a aprender. In: HSM management, São Paulo: HSM, n.9, ano 2, jul/ago 1998.

Aprendizagem em ação: um guia para transformar sua empresa em uma learning organization. Rio de Janeiro: Qualitymark, 2002

HOLMBERG, Börje. Distance Education as a Guided Conversation. Londres: Croom Helm, 1983.

KAYE, A. Analysing Distance Learning Systems. Londres: Open University, 1979.

KIM, D.H. O elo entre aprendizagem individual e organizacional em D. Klein. A gestão estratégica do capital intelectual. Rio de Janeiro: Qualitymark, 1998.

MOORE, M.; KEARSLEY, G. Distance education: a systems view. Belmont: Wadsworth Publishing Co., 1996.

MORAN, J.M. $O$ que é educação à distância. Esse texto foi publicado a primeira vez com o título: Novos caminhos do ensino à distância, no informe CEAD- Centro de educação a Distância. SENAI, Rio de Janeiro, ano1, n.5 out-dez. 1994, p. 1-3. Foi atualizado tanto o texto como bibliografia em 2002.

NEVIS, Edwin C.; DIBELLA, Anthonhy J.; GOULD, Janet M. Como entender organizações como sistemas de aprendizagem. In: KLEIN, David A. (org) A gestão estratégica do capital intelectual. Rio de Janeiro: Qualitymark, 1998.

NONAKA, I TAKEUCHI, H. The knowledge creating company. New York: Oxford University Press, 1995.

PAWLOWSKY, P. The Treatment of organizational learning. In management science. In:

POLAK, Y.N.S (Org); MARTINS, O.B. Fundamentos e políticas da educação e seus reflexos na educação à distância. Curso de formação em educação á distância -UNIREDE: Módulo 1, 1ed. Curitiba: MEC/SEED, 2000, v.1, 230p.

PROBST, G.J.B. BÜCHEL, B.S.T. Organizational Learning The competitive advantage of the future. New York: Prentice Hall, 1997.

SLATER, S. NARVER, J.C. Market orientation and the learning organization. Journal of Marketing, v. 59, p. 63-74, 1995.

STEIL, Andrea Valéria; PILLON, Ana Elisa; KERN, Vinícius Medina. Atitudes com relação à educação à distância em uma universidade. Psicol. estud., Maringá, v. 10, n. 2, 2005. Disponível em: <http://www.scielo.br

ULRICH, Dave. VONGLINOW, Mary A. Hight-impact learning: buiding and diffusing learning capability. Organizational Dynamics, v. 22, n.2, p. 52-67, 1993 